\title{
Focal plant and neighbourhood fruit crop size effects on fruit removal by frugivores in a semi-arid landscape invaded by Lantana camara L.
}

\author{
Geetha Ramaswami $^{1, *}$, Brihadeesh Santharam ${ }^{2}$ and Suhel Quader ${ }^{1}$ \\ ${ }^{1}$ Nature Conservation Foundation, Mysuru 570 002, India \\ ${ }^{2}$ Wildlife Institute of India, Dehradun 248 002, India
}

Mutualistic associations between frugivorous vertebrates and fleshy-fruited plants result in seed dispersal, a vital ecological process affecting plant populations and communities. Invasive fleshy-fruited plants can easily integrate into existing mutualistic networks if generalist frugivorous species start consuming invasive fruit. Additionally, the presence of a copiously fruiting invasive plant in the neighbourhood of fruiting native plants could affect the fruit removal from such plants by either reducing (competitive interaction), increasing (facilitative interaction) or not affecting (no interaction) visits by frugivorous vertebrates. In this study, we explore the effects of the presence of a fruiting invasive shrub Lantana camara L. in the neighbourhood of fruiting native species Erythroxylum monogynum Roxb. and Flueggea leucopyrus Willd. on the visit and fruit removal rate by avian frugivores in a semi-arid bird preserve in southern India. We conducted plant watches within fruiting patches of $30 \mathrm{~m}$ radius and observed the identity, numbers and fruit-handling behaviour by avian frugivores on focal native plants. We found that, on average, for the same fruit crop size, $E$. monogynum received more visits and more fruit removal than $F$. leucopyrus irrespective of the presence of fruiting neighbours. Focal tree fruit crop size was a better predictor of frugivore behaviour than the fruit crop size of neighbouring plants (both native and invasive) and was positively associated with frugivore visit rate and fruit removal from focal plants. We infer that there is little evidence for facilitation or competition by invasive neighbours for the dispersal services of vertebrate mutualists at the spatial and temporal scale examined in this study. Longer-term, larger-scale data are required to assess the changing impacts of invasive plants on native plant-frugivore interactions.

Keywords: Fruiting neighbourhood, invasive plant, Lantana camara, plant-frugivore association, semi-arid landscape.

*For correspondence. (e-mail: geetha@ncf-india.org)
SEED dispersal by vertebrate dispersers serves to maintain plant populations and communities by influencing processes such as colonization of new habitats, regulating gene flow, species interactions and species co-existence ${ }^{1-3}$. Long-distance dispersal by vertebrates also serves to move seeds between favourable sites, such as between forest fragments, and thus escape consequences of anthropogenic habitat modification and even climate change ${ }^{4,5}$. Avian frugivores are an important subset of vertebrate dispersers of fleshy-fruited plants across the world. Avian dispersers can bring about changes such as primary and secondary succession of plants, forest regeneration and directed dispersal of seeds to favourable microsites ${ }^{6}$.

Fruit removal (and consequently seed dispersal) from plants is influenced by plant characteristics such as fruit quantity and fruit quality, and frugivore characteristics such as gape width and body size ${ }^{7-9}$. In addition to high fruit availability at individual fruiting plants, the spatial clustering of fruiting plants and the presence of fruiting neighbours has also been shown to influence fruit removal. For example, the efficacy of fruit removal from individual plants with low fruit crop size has been shown to be higher when surrounded by more fruiting conspecifics ${ }^{10}$, i.e. the presence of fruiting neighbours facilitated removal from focal plants. Conversely, competitive interaction between conspecifics, i.e. reduced removal from focal plants in the presence of high densities of fruiting neighbours has also been demonstrated ${ }^{11}$. At the patch level, aggregation of fruiting plants may affect seed dispersal distances. Aggregation, or the presence of multiple fruiting plants close together, may result in frugivores spending more time foraging within such fruiting patches, and this may, in turn, lead to lower average dispersal distances if the avian frugivore also has a short average gut passage time ${ }^{12,13}$.

While a number of studies have looked at the effects of conspecific neighbours on fruit removal from focal plants, the role of heterospecific neighbours and especially invasive fleshy-fruited plants is widely understudied. Native avian frugivores are often generalist and can rapidly form 
mutualistic associations with exotic and invasive species by including such fruits into their diets ${ }^{14-18}$. Frugivore switches in preference for invasive fruits may eventually lead to lower visit rates and fruit removal from native plants ${ }^{19-21}$. Thus, a fruiting patch dominated by invasive plants may result in poorer dispersal of native seeds from such a patch.

Lantana camara L. (Lantana hereon, Verbenaceae) is a thorny, scrambling woody plant and is recognized as one amongst the worst shrub invaders of the world ${ }^{22}$. Originally from the tropical Americas, Lantana was introduced into the Indian subcontinent in the early 1800 s and has since then become widely invasive across forests and agricultural land ${ }^{23,24}$. Lantana produces large quantities of small, sweet, purple-black berries and has thus become associated with a number of generalist avian frugivore groups such as bulbuls ${ }^{25,26}$ and has also become part of native plant-frugivore networks ${ }^{27-29}$. Additionally, Lantana grows in highly aggregated dense thickets of individual plants, often forming contiguous fruiting patches around native fleshy fruited plants (pers. obs.). The presence of this attractive invasive plant in the neighbourhood of native species is thus likely to influence visitation and fruit removal by avian frugivores at native plants.

In this study, we use Lantana and two co-occurring native species - Erythroxylum monogynum Roxb. (Erythroxylaceae) and Flueggea leucopyrus Willd. (Phyllantahceae) that produce fleshy fruits in order to answer the following questions: (1) Does the presence of fruiting neighbours affect frugivore visits to and fruit removal from fruiting plants? (2) Does the presence of fruiting Lantana neighbours alter rates of visits to and fruit removal from native fruiting plants?

\section{Methods}

\section{Study site}

This study was conducted in and around the campus of the Rishi Valley School, located in Andhra Pradesh, India $\left(16^{\prime} 63^{\prime \prime} \mathrm{N}, 7^{\prime} 45^{\prime \prime} \mathrm{E}\right)$. The valley is characterized by dry-thorny habitat adapted to low, seasonal rainfall conditions. The vegetation on the closest western hillock has been preserved by fencing against grazing animals and has been extensively re-forested. The preserve is about 60 ha in area and has an understorey consisting of a number of native fleshy-fruited shrubs such as Catunaregam spinosa (Thunb.) Tirveng. (Rubiaceae), Flacourtia indica (Burm.f.) Merr. (Salicaceae) and E. monogynum. Lantana is one amongst the five most abundant shrubs in the preserve ${ }^{29}$. The native plant species composition within the preserve is comparable to that of two nearby reserve forests - Kurabalakota and Tarigonda (area = 140.8 ha and 2699.8 ha respectively) - and thus repre- sentative of the larger landscape and species interactions (unpublished data). Kurabalakota has high densities of Lantana and F. leucopyrus while Catunaregam spinosa and Lantana are the most abundant shrubs at Tarigonda (densities estimated using point centre quarter method along systematically laid $500 \mathrm{~m}$ transects in these reserve forests; unpublished data).

\section{Study species}

Three native, fleshy-fruited, vertebrate-dispersed shrub species, E.monogynum, F. leucopyrus and F. indica, were chosen for focal observations based on their overlapping fruiting phenology with Lantana. E. monogynum, $F$. indica and $F$. leucopyus fruit between August and November each year with single or multiple fruiting peaks (based on 9-year phenology data collected in the valley between 2008 and 2016; unpublished data). Lantana also typically fruits in this duration and exhibits multiple fruiting peaks. All four species have typically birddispersed fruit characteristics ${ }^{29}$. During this study, fruiting individuals of E. monogynum were observed between July and August 2016, F. leucopyrus was observed in September 2016 and $F$. indica were observed in October 2016. However, the frugivore visit rate and fruit removal from $F$. indica patches were extremely low and we did not include this species in further analyses or inference. Lantana fruiting overlapped with all the native species observed.

\section{Field methods}

Characterizing plant neighbourhoods: Focal plants were observed within circles of $30 \mathrm{~m}$ radius, henceforth referred to as 'patches'. The size of the patch is based on estimated median dispersal distance of seeds by small frugivorous birds that occur in the habitat ${ }^{26}$. Patch centres were selected in the field, at random, such that within the $30 \mathrm{~m}$ radius, at least three fruiting individuals of a given species of interest were present. Around each of the three focal plants within a patch, $5 \mathrm{~m}$ and $10 \mathrm{~m}$ annuli were made with the focal plant as the centre. Within each annulus, all vertebrate-dispersed fruiting neighbours (native species - primarily E. monogynum, F. leucopyrus and $F$. leucopyrus and invasive Lantana) were identified. Since tens of fruiting trees could be present in a $10 \mathrm{~m}$ annulus around a focal tree, it was not possible to estimate the exact fruit crop size for all individuals and simultaneously make observations on frugivores in the short feeding window of birds. Additionally, in a previous study, we had reported that a tenfold increase in fruit crop size of focal plants was required to detect a unit change in frugivore visit rate and fruit removal rate ${ }^{29}$. In order to circumvent the observation problem, and keeping in mind that a tenfold increase in crop size was required to 
observe an effect, we quantified the number of fruits on focal plants and each neighbour as belonging to one of the following fruit-crop size classes: $0,1-10,10-100$, 100-1000, 1000-10,000, 10,000-100,000. Observations on 28 focal plants across 8 patches for E. monogynum, 24 plants across 8 patches for $F$. leucopyrus and 16 plants across 5 patches for $F$. indica were made.

Plant watches: Each focal plant was observed for 3 hours, between 0600 and 1100 am or from 1500 to $1800 \mathrm{pm}$, when bird feeding activity was expected to be highest. A few plants were observed in two sessions on a single day for a cumulative duration of $3 \mathrm{~h}$. The observer sat well concealed, at a distance of at least $10 \mathrm{~m}$ from the focal plant and used a pair of binoculars to make observations. Scan and focal sampling were used to measure frugivore behaviour at focal plants. Number and species identity of visiting birds on focal plants was noted during scans taken once every $10 \mathrm{~min}$. Focal samples involved observing a single bird from the time it arrived on a plant until the time it left (or for the duration that it was visible in the shrub canopy). The fruit handling behaviour of the frugivore was observed, i.e. the number of fruits it swallowed, pecked, chewed or dropped were counted. 'Swallowed' fruits were also most likely to be dispersed and were thus used as a measure of fruit removal from the plant.

\section{Analyses}

To meaningfully assess the effect of fruit-crop size on frugivore behaviour, the qualitative size bins were converted to a quantitative index by taking the $\log$ (base 10 ) of the mid-point of the bin. For example, a tree belonging to the size class bin 10-100, had a fruit crop size index of 1.7 (i.e. $\log 10(50)$ ). Each fruiting plant within an annulus thus had a fruiting index score ranging from 1.7 $(\log 10(50))$ to $4.7(=\log 10(5000))$ since bins ranged from $10-100$ to $10,000-100,000$. The total magnitude of native neighbour crop size was estimated as the sum of all native plant fruit crop size indices within $10 \mathrm{~m}$ and $5 \mathrm{~m}$ annuli around a focal plant. Total fruit-crop size for invasive neighbours was estimated as the sum of all Lantana fruit crop size indices within $10 \mathrm{~m}$ and $5 \mathrm{~m}$ annuli around a focal plant. The $\log ($ base 10$)$ conversion was once again justified on the basis of our previous observations wherein a tenfold increase in crop size was required to detect unit change in frugivore behaviour.

Models reported here are based on interactions between three species only: Lantana, E. monogynum and $F$. leucopyrus. Frugivore visit rate (number of frugivore visits per session of observation, $180 \mathrm{~min}$ ) and fruit removal (by all frugivores per observation session, $180 \mathrm{~min}$ ) were modelled as a function of focal plant fruitcrop size index, focal plant species identity and neigh- bourhood native plant and Lantana fruit-crop size index in a generalized mixed effects framework with a negative binomial error structure. To control for possible withingroup similarities in response to spatial proximity, patch identity was specified as a random effect. A few plants were observed for slightly more or less than $180 \mathrm{~min}$, either due to weather conditions or due to erroneous time difference calculation from start time. To account for the differences in observation times, a time duration offset was added to all the models. To assess whether invasive Lantana particularly affected visits to focal plants, another set of models with focal plant fruit-crop size and crop-size of all Lantana neighbours was also made. To assess whether neighbours closer to focal plants affected visitation, both the above sets of models were created, but with neighbours within the $5 \mathrm{~m}$ annulus. Effect sizes were considered to be discernible if bootstrapped 95\% CIs did not overlap zero. We also ran the same set of models without species identity as a fixed effect to assess overall effects of focal and neighbourhood fruit crop sizes on removal from both native species. All analyses were performed in $\mathrm{R}$ (version 3.3.2, 2016).

\section{Results}

\section{Frugivore assemblage at focal plants}

Twelve species of birds and one mammal visited the focal plants during our observations (Table 1). Several nonfrugivorous bird species visited focal plants but did not contribute to fruit removal in terms of swallowing fruits. Bird species that contributed most to the removal of fruits from focal plants (Table 1) included the pale-billed flowerpecker (Dicaeum erythrorhynchos), white-browed bulbul (Pycnonotus luteolus) and red-vented bulbul (Pycnonotus cafer). The three-striped palm squirrel (Funambulus palmarum) is a rodent and expected to be a seed predator and not a disperser. The visiting individual chewed on, but did not swallow any fruits from focal plants. A number of visitors handled (pecked, chewed or dropped) fruits, but did not contribute to fruit removal by swallowing or carrying the fruit away from the focal plant (Table 1).

\section{Frugivore visit rate and fruit removal}

Models predicting frugivore visits performed well overall, with high correlation between predicted and observed values (Table 2). Models predicting fruit removal performed poorly overall, with low correlation between fitted and observed values (Table 2). In all models, there appeared to be no discernible effect of neighbourhood fruit crop size on frugivore visits and fruit removal from a focal plant, as the $95 \%$ CI for this parameter always overlapped zero (Table 2). The same was 
RESEARCH ARTICLES

Appendix 1. Model coefficients for models predicting dispersal and visit rates (number of fruits removed and number of avian visitors per $3 \mathrm{~h}$ observation session respectively) as a function of fruit abundance of focal and neighbourhood plants within $10 \mathrm{~m}$ and $5 \mathrm{~m}$ annuli. Patch identity was the only random effect assessed in all models. Predictors with discernible effects are highlighted in boldface text

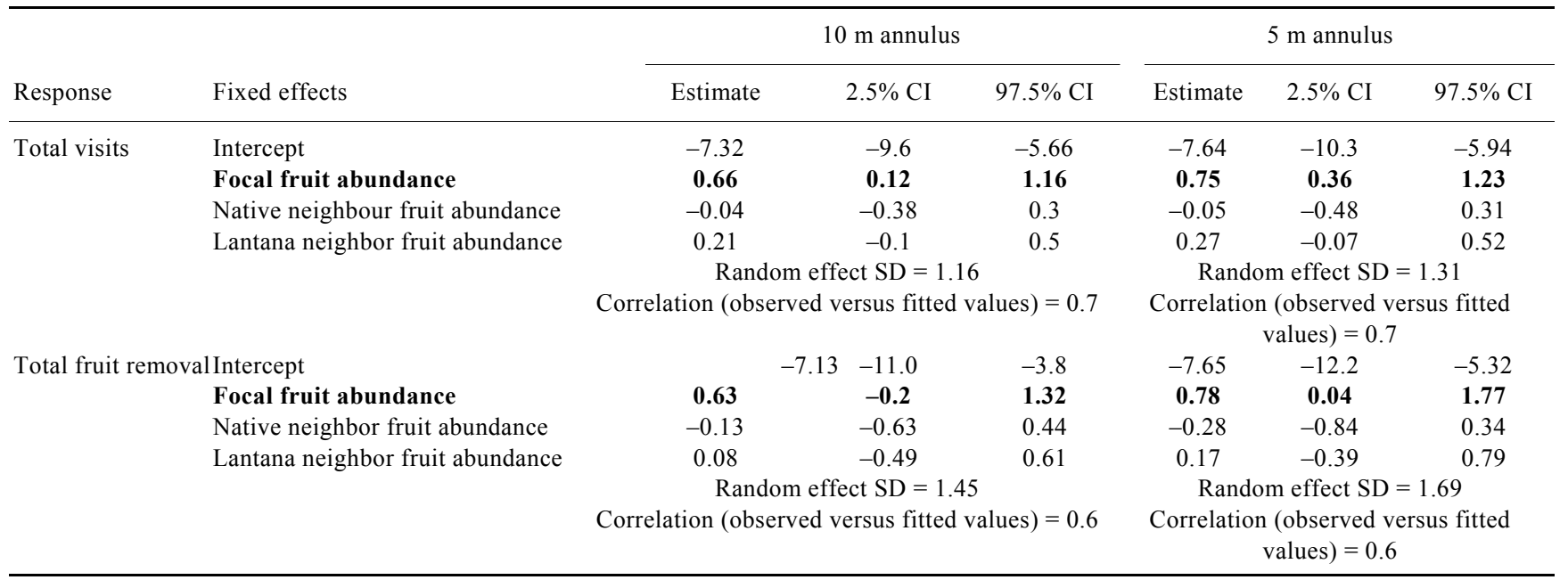
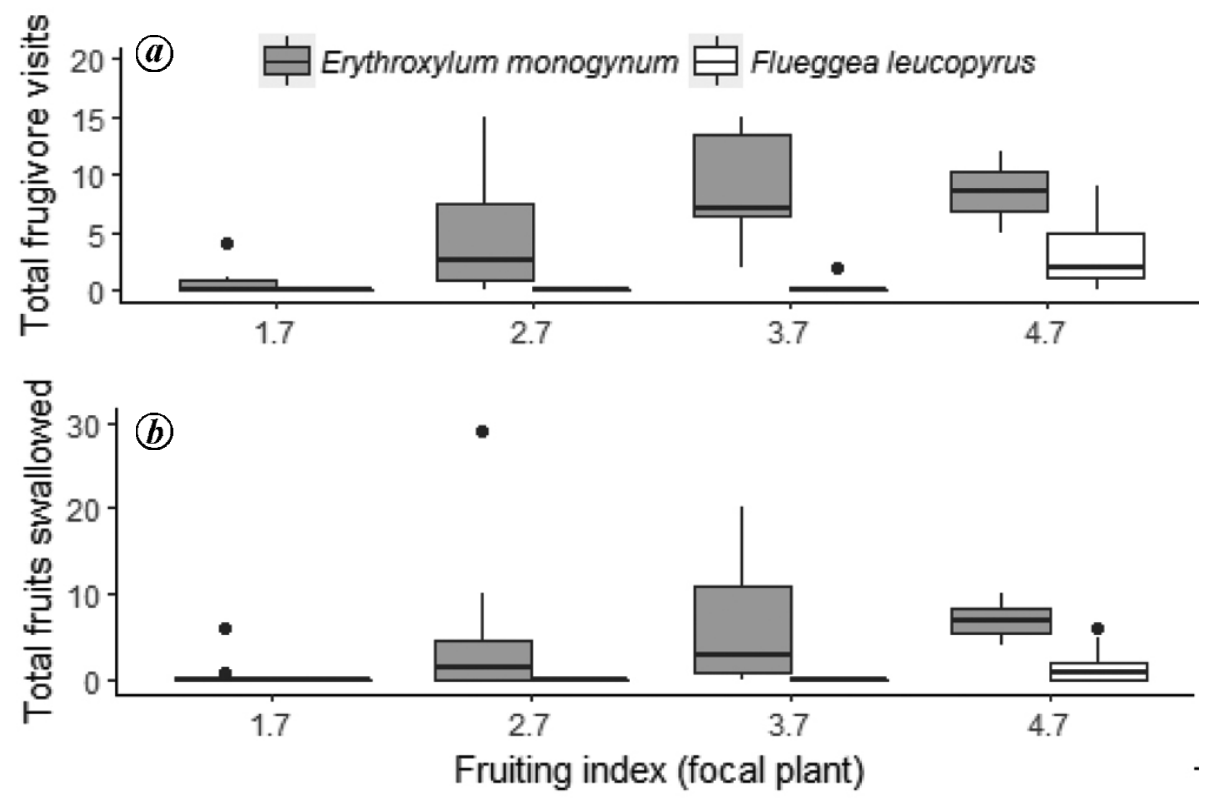

Figure 1. (a) Frugivore visit rates and (b) fruit removal measured as the number of fruits swallowed as a function of focal plant fruit crop size of two native plants, Erythroxylum monogynum and Flueggea leucpyrus in the presence of fruiting neighbours, including invasive Lantana. Note that the $y$-axes correspond to the total number of visits and fruits removed by all frugivores observed in a session of $180 \mathrm{~min}$. The $x$-axes correspond to the $\log$ (base 10) value of the midpoint of focal plant fruit crop size bin.

rate and the number of fruits they remove across space and time - which in turn is positively affected by fruit quantity of shrubs ${ }^{29-33}$. In this study, we explored how frugivore behaviour (and therefore fruit removal) might be affected by the crop size of focal plants as well as that of neighbouring heterospecifics. Additionally, we focused specifically on the crop size of neighbouring Lantana, to study whether this invasive plant has a disproportionate effect on frugivore behaviour. We report that frugivore visitation to and fruit removal from focal plants was positively correlated with fruit crop size. We have reported similar results at the level of the fleshyfruited shrub community as a whole in this landscape in an earlier study as well ${ }^{29}$.

Our main objective was to assess the effects of invasive Lantana in the neighbourhood on fruit removal from native plants. To this end, two native species, E. monogynum and $F$. leucopyrus, similar in fruiting duration and fruit characteristics to Lantana ${ }^{29}$ were chosen. Overall visit rate to E. monogynum was low and similar to that reported in its congener E. ambiguum, although, much higher seed dispersal efficiency has been reported for the 


\section{RESEARCH ARTICLES}

latter species ${ }^{34}$. We also found a clear difference in visits to and removal from the two target native species $F$. leucopyrus and E. monogynum. E. monogynum consistently received more visits by frugivores and experienced higher fruit removal than $F$. leucopyrus (Figure $1 a$ and $b$ ). Between-species differences reflected in the statistical models could be because of no removal from $F$. leucopyrus in the lower fruit crop size classes but highly variable visits to and removal from higher fruit crop size classes (Figure $1 a$ and $b$ ). In a previous study conducted during JuneDecember 2015, however, we had found fruit removal from $F$. leucopyrus to be much higher than that of $E$. $m o$ nogynum $^{29}$. We speculate that these inconsistent differences are a consequence of inter-annual variability in fruit availability and frugivore visitation ${ }^{35}$. We infer that more temporal replicates of observations on these species are required to assess true preference for either plant species by avian frugivores.

When the fruit crop size of invasive neighbours was considered, we found that the quantity of fruits on fruiting Lantana neighbours did not have a discernible effect on fruit removal from focal plants. Similar responses have been observed for Eugenia uniflora, wherein the focal plant fruit crop size had a higher positive effect on frugivore behaviour compared to the fruit crop size of conspecific and heterospecific neighbours ${ }^{10}$. Studies from elsewhere report preferential frugivore visitation to co-fruiting invasive species over native fruiting shrubs, and that invasive species receive up to half of all observed visits by frugivores ${ }^{20,28,36}$. Preference for invasive species has been attributed to greater variability among fruit traits, or higher nutritional content compared with native plants ${ }^{19,37}$. However, the quality of Lantana fruits (in terms of fruit size, pulp weight and crude sugar content) in our study area is similar to the two native species examined here ${ }^{29}$, and may thus not be a more attractive food source than the fruits of native plants. However, understanding the interactions between native and invasive plants and acknowledging that native frugivores have become dependent on invasive plants for food resources, could eventually inform management decisions. For instance, species most similar to Lantana in terms of fruit characteristics could be used to restore sites from where the invasive plant has been removed ${ }^{17,38}$.

We infer that, for our study landscape, higher densities of invasive fruits in the neighbourhood did not result in higher (facilitative) or lower (competitive) fruit removal from focal plants. Plant-frugivore interactions are bound to change with changing plant and frugivore densities and clustering in space and time ${ }^{12,39}$. Furthermore, the larger landscape and habitat context in which common frugivores select fruiting patches may affect frugivore visitation to fruiting plants. One may thus observe a consequent difference in the nature of interactions between native and invasive species as well. We conclude that more temporal (across different fruiting seasons) and spatial replicates (across different spatial scales and habitats) of fruiting patches are required to assess if the interactions between Lantana and co-fruiting native species are indeed neutral across space and time.

1. Nathan, R. and Muller-Landau, H. C., Spatial patterns of seed dispersal, their determinants and consequences for recruitment. Trends Ecol. Evol., 2000, 15, 278-285.

2. Levine, J. M. and Murrell, D. J., The community-level consequences of seed dispersal patterns. Annu. Rev. Ecol., Evol. Syst., 2003, 34, 549-574.

3. Bascompte, J., Jordano, P. and Olesen, J. M., Asymmetric coevolutionary networks facilitate biodiversity maintenance. Science, 2006, 312, 431-433.

4. Pearson, R. G. and Dawson, T. P., Long-distance plant dispersal and habitat fragmentation: identifying conservation targets for spatial landscape planning under climate change. Biol. Conserv., 2005, 123, 389-401.

5. Levey, D. J., Bolker, B. M., Tewksbury, J. J., Sargent, S. and Haddad, N. M., Effects of landscape corridors on seed dispersal by birds. Science, 2005, 309, 146-148.

6. Wenny, D. G., Sekercioglu, Ç. H., Cordeiro, N. J., Rogers, H. S. and Kelly, D., Seed dispersal by fruit-eating birds. In Why Birds Matter: Avian Ecological Function and Ecosystem Services, University of Chicago Press, Chicago, 2016.

7. Burns, K. C., What causes size coupling in fruit-frugivore interaction webs? Ecology, 2013, 94, 295-300.

8. Bello, C. et al., Atlantic frugivory: a plant-frugivore interaction data set for the Atlantic Forest. Ecology, 2017, 98, 1729-1729.

9. Schaefer, H. M., Schmidt, V. and Winkler, H., Testing the defence trade-off hypothesis: how contents of nutrients and secondary compounds affect fruit removal. Oikos, 2003, 102, 318-328.

10. Blendinger, P. G., Loiselle, B. A. and Blake, J. G., Crop size, plant aggregation, and microhabitat type affect fruit removal by birds from individual melastome plants in the Upper Amazon. Oecologia, 2008, 158, 273-283.

11. Smith, A. D. and McWilliams, S. R., Fruit removal rate depends on neighborhood fruit density, frugivore abundance, and spatial context. Oecologia, 2014, 174, 931-942.

12. Morales, J. M. and Carlo, T. A., The effects of plant distribution and frugivore density on the scale and shape of dispersal kernels. Ecology, 2006, 87, 1489-1496.

13. Morales, J. M., Rivarola, M. D., Amico, G. and Carlo, T. A., Neighborhood effects on seed dispersal by frugivores: testing theory with a mistletoe-marsupial system in Patagonia. Ecology, 2012, 93, 741-748.

14. Richardson, D. M., Allsopp, N., D’Antonio, C. M., Milton, S. J. and Rejmánek, M., Plant invasions - the role of mutualisms. Biol. Rev. Camb. Philos. Soc., 2000, 75, 65-93.

15. Traveset, A. and Richardson, D. M., Biological invasions as disruptors of plant reproductive mutualisms. Trends Ecol. Evol., 2006, 21, 208-216.

16. Bascompte, J. and Jordano, P., Plant-animal mutualistic networks: the architecture of biodiversity. Ann. Rev. Ecol., Evol. Syst., 2007, 38, 567-593.

17. Buckley, Y. M. et al., Management of plant invasions mediated by frugivore interactions. J. Appl. Ecol., 2006, 43, 848-857.

18. Davis, M., Do native birds care whether their berries are native or exotic? No. BioScience, 2011, 61, 501-502.

19. Kueffer, C., Kronauer, L. and Edwards, P. J., Wider spectrum of fruit traits in invasive than native floras may increase the vulnerability of oceanic islands to plant invasions. Oikos, 2009, 118, $1327-1334$

20. Mokotjomela, T. M., Musil, C. F. and Esler, K. J., Frugivorous birds visit fruits of emerging alien shrub species more frequently 
than those of native shrub species in the South African Mediterranean climate region. S. Afr. J. Bot., 2013, 86, 73-78.

21. Traveset, A. and Richardson, D. M., Mutualistic interactions and biological invasions. Ann. Rev. Ecol., Evol. Syst., 2014, 45, 89113.

22. Richardson, D. M. and Rejmánek, M., Trees and shrubs as invasive alien species - a global review. Div. Distrib., 2011, 17, 788809.

23. Bhagwat, S. A., Breman, E., Thekaekara, T., Thornton, T. F. and Willis, K. J., A battle lost? Report on two centuries of invasion and management of Lantana camara L. in Australia, India and South Africa. PLoS ONE, 2012, 7, e32407.

24. Kannan, R., Shackleton, C. M. and Shaanker, R. U., Reconstructing the history of introduction and spread of the invasive species, Lantana, at three spatial scales in India. Biol. Invasions, 2013, 15, $1287-1302$.

25. Aravind, N. A., Rao, D., Ganeshaiah, K. N., Uma Shaanker, R. and Poulsen, J. G., Impact of the invasive plant, Lantana camara, on bird assemblages at Male Mahadeshwara Reserve Forest, South India. Trop. Ecol., 2010, 51, 325-338.

26. Ramaswami, G., Kaushik, M., Prasad, S., Sukumar, R. and Westcott, D., Dispersal by generalist frugivores affects management of an invasive plant. Biotropica, 2016, 48, 638-644.

27. Chimera, C. G. and Drake, D. R., Patterns of seed dispersal and dispersal failure in a Hawaiian dry forest having only introduced birds. Biotropica, 2010, 42, 493-502.

28. Heleno, R. H., Ramos, J. A. and Memmott, J., Integration of exotic seeds into an Azorean seed dispersal network. Biol. Invasions, 2013, 15, 1143-1154.

29. Ramaswami, G., Somnath, P. and Quader, S., Plant-disperser mutualisms in a semi-arid habitat invaded by Lantana camara L. Plant Ecol., 2017, 218, 935-946.

30. Davidar, P. and Morton, E. S., The relationship between fruit crop sizes and fruit removal rates by birds. Ecology, 1986, 67, 262265.

31. Murray, K. G., Selection for optimal fruit-crop size in birddispersed plants. Am. Nat., 1987, 129, 18-31.

32. Willson, M. F. and Whelan, C. J., Variation of dispersal phenology in a bird-dispersed shrub, Cornus drummondii. Ecol. Monographs, 1993, 63, 151-172.
33. Ortiz-Pulido, R. and Rico-Gray, V., The effect of spatio-temporal variation in understanding the fruit crop size hypothesis. Oikos, 2000, 91, 523-527.

34. Camargo, P. H., Martins, M. M., Feitosa, R. M. and Christianini, A. V., Bird and ant synergy increases the seed dispersal effectiveness of an ornithochoric shrub. Oecologia, 2016, 181, 507-518.

35. Prasad, S. and Sukumar, R., Context-dependency of a complex fruit-frugivore mutualism: temporal variation in crop size and neighborhood effects. Oikos, 2010, 119, 514-523.

36. Aslan, C. E. and Rejmánek, M., Avian use of introduced plants: ornithologist records illuminate interspecific associations and research needs. Ecol. Appl, 2010, 20, 1005-1020.

37. Jordaan, L. A. and Downs, C. T., Nutritional and morphological traits of invasive and exotic fleshy-fruits in South Africa. Biotropica, 2012, 44, 738-743.

38. Gosper, C. R. and Vivian-Smith, G., Selecting replacements for invasive plants to support frugivores in highly modified sites: a case study focusing on Lantana camara. Ecol. Manage. Restor., 2006, 7, 197-203.

39. Carlo, T. A. and Morales, J. M., Inequalities in fruit-removal and seed dispersal: consequences of bird behaviour, neighbourhood density and landscape aggregation. J. Ecol., 2008, 96, 609-618.

ACKNOWLEDGEMENTS. We thank the Department of Science and Technology: Science and Engineering Research Board, Government of India for funding this project. The Andhra Pradesh Forest Department kindly permitted us to work at the Tarigonda and Kurabalakota reserve forests, and we thank Alitha Edison for surveying and estimating plant densities in this area. We thank P. Somnath and Lavina Datta for help with data collection. The Rishi Valley School provided logistical support and facilitated this study.

Received 18 April 2018; revised accepted 17 October 2018

doi: $10.18520 / \mathrm{cs} / \mathrm{v} 116 / \mathrm{i} 3 / 405-411$ 